NASA/TM-2015-218992

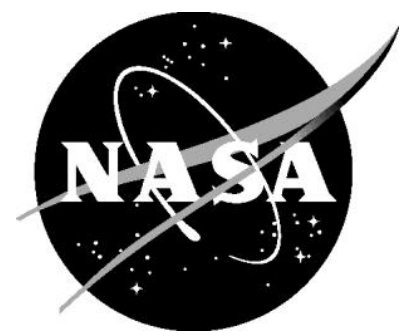

\title{
Morphological Processing of Ultraviolet Emissions of Electrical Corona Discharge for Analysis and Diagnostic Use
}

Matthew R. Schubert

Analytical Mechanics Associates, Inc., Hampton, Virginia

Andrew J. Moore

Langley Research Center, Hampton, Virginia 


\section{NASA STI Program . . . in Profile}

Since its founding, NASA has been dedicated to the advancement of aeronautics and space science. The NASA scientific and technical information (STI) program plays a key part in helping NASA maintain this important role.

The NASA STI program operates under the auspices of the Agency Chief Information Officer. It collects, organizes, provides for archiving, and disseminates NASA's STI. The NASA STI program provides access to the NTRS Registered and its public interface, the NASA Technical Reports Server, thus providing one of the largest collections of aeronautical and space science STI in the world. Results are published in both non-NASA channels and by NASA in the NASA STI Report Series, which includes the following report types:

- TECHNICAL PUBLICATION. Reports of completed research or a major significant phase of research that present the results of NASA Programs and include extensive data or theoretical analysis. Includes compilations of significant scientific and technical data and information deemed to be of continuing reference value. NASA counter-part of peer-reviewed formal professional papers but has less stringent limitations on manuscript length and extent of graphic presentations.

\section{- TECHNICAL MEMORANDUM.}

Scientific and technical findings that are preliminary or of specialized interest, e.g., quick release reports, working papers, and bibliographies that contain minimal annotation. Does not contain extensive analysis.

- CONTRACTOR REPORT. Scientific and technical findings by NASA-sponsored contractors and grantees.
- CONFERENCE PUBLICATION.

Collected papers from scientific and technical conferences, symposia, seminars, or other meetings sponsored or co-sponsored by NASA.

- SPECIAL PUBLICATION. Scientific, technical, or historical information from NASA programs, projects, and missions, often concerned with subjects having substantial public interest.

- TECHNICAL TRANSLATION. English-language translations of foreign scientific and technical material pertinent to NASA's mission.

Specialized services also include organizing and publishing research results, distributing specialized research announcements and feeds, providing information desk and personal search support, and enabling data exchange services.

For more information about the NASA STI program, see the following:

- Access the NASA STI program home page at http://www.sti.nasa.gov

- E-mail your question to help@ @sti.nasa.gov

- Phone the NASA STI Information Desk at 757-864-9658

- Write to:

NASA STI Information Desk

Mail Stop 148

NASA Langley Research Center

Hampton, VA 23681-2199 
NASA/TM-2015-218992

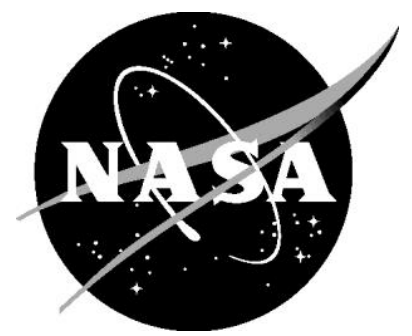

\section{Morphological Processing of Ultraviolet Emissions of Electrical Corona Discharge for Analysis and Diagnostic Use}

Matthew R. Schubert

Analytical Mechanics Associates, Inc., Hampton, Virginia

Andrew J. Moore

Langley Research Center, Hampton, Virginia

National Aeronautics and

Space Administration

Langley Research Center

Hampton, Virginia 23681-2199 


\section{Acknowledgments}

We thank the Dominion Electric Transmission Forestry \& Line Services team for test imagery and helpful discussions about diagnostics, Fabio Bologna and Andrew Phillips of the Electric Power Research Institute for discussions on phenomenology, Taumi Daniels of NASA for discussions on plasma physics, and Scott Dorsey of NASA for discussions on corona generation. This work was performed as part of the NASA Safe Autonomous Systems Operation program.

The use of trademarks or names of manufacturers in this report is for accurate reporting and does not constitute an official endorsement, either expressed or implied, of such products or manufacturers by the National Aeronautics and Space Administration.

Available from:

NASA STI Program / Mail Stop 148

NASA Langley Research Center

Hampton, VA 23681-2199

Fax: 757-864-6500 


\section{Morphological processing of ultraviolet emissions of electrical corona discharge for analysis and diagnostic use}

Abstract-Electron cascades from electrical discharge produce secondary emissions from atmospheric plasma in the ultraviolet band. For a single point of discharge, these emissions exhibit a stereotypical discharge morphology, with latent information about the discharge location. Morphological processing can uncover the location and therefore can have diagnostic utility.

Index Terms-- Ultraviolet; Optical sensing and sensors; Image processing; Industrial inspection

\section{INTRODUCTION}

In electrical power transmission, great care is taken to avoid sharp protrusions on structures that are on or near high voltage conductors, to avoid a local concentration of the electric field that exceeds the threshold for coronal discharge. Electron avalanches from high-potential points produce, via impact ionization and subsequent recombination of atmospheric plasma, an ultraviolet (UV) photon spray. While most coronas are benign, some are indicative of a severe degradation that requires immediate attention; location, diagnosis and disposition of coronas is a necessary component of transmission line inspection. However, this method is applied infrequently due to the cost and difficulty of image capture (commonly in remote areas) and due to the cost of human inspection of UV-band imagery. More frequent inspection of power transmission infrastructure may be possible by low-cost aerial (UAV) image capture and automated image analysis.

\section{PHYSICS OF CORONA FORMATION}

The dielectric response to a high $\mathrm{E}$ field is a complex, multi-regime phenomenon [1], particularly when the field arises from an alternating (e.g., $60 \mathrm{~Hz}$ ) source: cathodal and anodal coronas initiate, propagate and extinguish in each positive and negative half-cycle of alternation [2]. This letter describes morphological processing that automates UV-band corona analysis in the static discharge regime [3] in which the dielectric is air (at standard temperature and pressure) and in which the field gradient is insufficient, for a fixed source-to-sink distance, to produce spark-over or conductive shorting, as these are the conditions for which corona is difficult to locate and analyze. Coronal ionization/recombination sites decrease monotonically with distance $r$ from the initiation point; in a planar projection into the viewport of a UV imager, the photon distribution appears as a solid ball of emission in the nucleus and a speckled halo in the periphery [4].

\section{IMAGE PROCESSING TO LOCATE THE CORONA SOURCE}

Since the peripheral emission sites appear as blobs with an area much smaller than the center site, a simple erode-AND operation can extract the center [5]. However, in electrical inspection, visible-band imagery is needed to determine the corona cause, and the context of the corona is necessary. For example, adjacency to a high-voltage conductor, and surface conditions in the area surrounding the corona center are of critical diagnostic value; methods that remove information about the corona radius are of limited utility. In this paper we report two additional methods to determine the corona center, and a method to determine the entire extent of the corona emission image. 


\section{Center determination}

The first center-finding method of this study uses temporal averaging to accomplish via the time domain an analog to spatial erosion method of [5]. We found that for common camera settings, averaging frames over 1 second of $30 \mathrm{fps}$ video is sufficient to robustly lower the average intensity of peripheral emission sites, so that a blob test based on area and circularity followed by a persistence threshold $\theta$ removes all sites except the center, and uniquely identifies the center coordinates.

$$
C(x, y)=\int_{t}\left\{\operatorname{Area}[I(x, y)]>A_{\min }\right\}>\theta
$$

If the UV imager viewport is not stable, this method suffers from distortions, as image smearing over time expands and skews the time-integrated area.

The second center-finding method counts the number of maxima of image intensity after Gaussian blurring,

$$
C(x, y)=\max _{x, y}\left[G_{\sigma}(x, y) \otimes I(x, y)\right]
$$

increasing kernel width $\sigma$ until the count stabilizes to one; that maximum is taken as the center of the corona. (A related center-finding method conditions the increase in $\sigma$ on locational stability of maxima, but at low $\sigma$ this method falsely reports maxima at each site of peripheral emission, if the corona nucleus is not in the field of view.)

\section{Extent determination}

Corona extent varies with the gain of the UV imager multichannel plate [4][6]. To diagnostically determine a discharge location, human inspectors commonly i) start with a relatively high gain to find discharge figures, ii) lower the gain to remove stray ambient emissions and, if a characteristic radial morphology is recognized, iii) center the camera view on the coronal nucleus and iv) lower the gain further until only the center is visible and take a snapshot in the visible band with the UV nucleus overlaid. This sequence is based on the broadly reliable assumption that the corona nucleus is coincident with the high $\mathrm{E}$ field initiation point of the discharge, and effectively pinpoints the center within a diagnostic context.

To derive a computational basis with which to mimic the third and fourth steps of this behavior, we create an intermediate representation of corona morphology by applying a series of difference of box (DoB) filters with increasing size d, centered at the corona nucleus (Fig. 1). In this representation, if the DoB is balanced and the UV image is binary, the shape of the DoB score through scale indicates discharge isolation and morphological coherence. The positive extent of the DoB (central green boxes in Fig. 1) is a suitable frame for a detail snapshot in the visible band, while the negative extent (outer red boxes in Fig. 1) frames the contextual snapshot and can be used to prompt an operator to zoom out to capture the full diagnostic context (Fig. 1c).

To handle multiple coronas in a frame, if the area in (1) or the value of the center intensity in (2) (after zeroing the pixel values of the positive portion of the DoB; green in Fig. 1) is above the value expected for a corona nucleus, we repeat the DoB extent determination (Figs. 1d, 1e).

\section{REFERENCES}

1. Frank William Peek, Dielectric phenomena in high voltage engineering (McGraw-Hill), 1920.

2. E. W., Austen, and S. Whitehead, Discharges in Insulation Under Alternating-Current Stresses, Journal of the Institution of Electrical Engineers III, 88(1), (1941), pp. 18-22.

3. Erich E. Kunhardt, Electrical Breakdown of Gases: The Prebreakdown Stage, IEEE Plasma Science 8(3) (1980), pp. 130-138. 
4. K. M. Shong, Y. S. Kim, and S. G. Kim, Images Detection and Diagnosis of Corona Discharge on Porcelain Insulators at 22.9kV D/L, IEEE Int. Symp. SDEMPED 2007, pp. 462466

5. B. Hu, L-X. Ma, S-J Yuan, and B. Yang, New corona ultraviolet detection system and fault location method, in Electricity Distribution (CICED), 2012 China International Conference on, (IEEE, 2012), pp. 1-4.

6. Y. Kim, and K. Shong, The Characteristics of UV Strength According to Corona Discharge From Polymer Insulators Using a UV Sensor and Optic Lens, IEEE Trans. Power Delivery, 26(3), (2011), pp. 1579-1584.
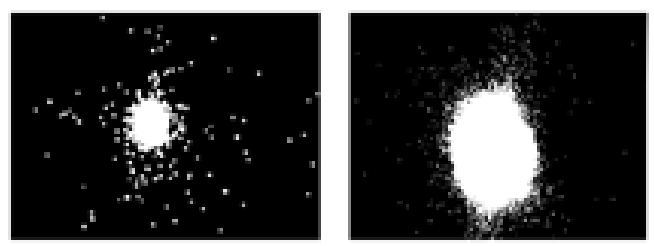

(a)
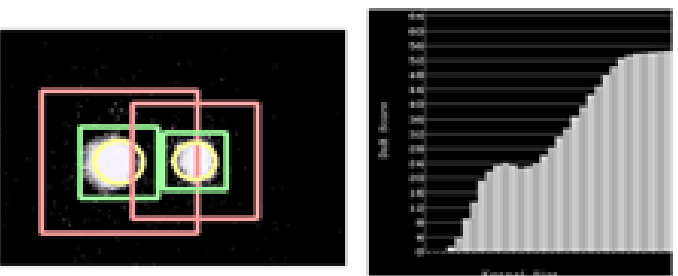

(d)
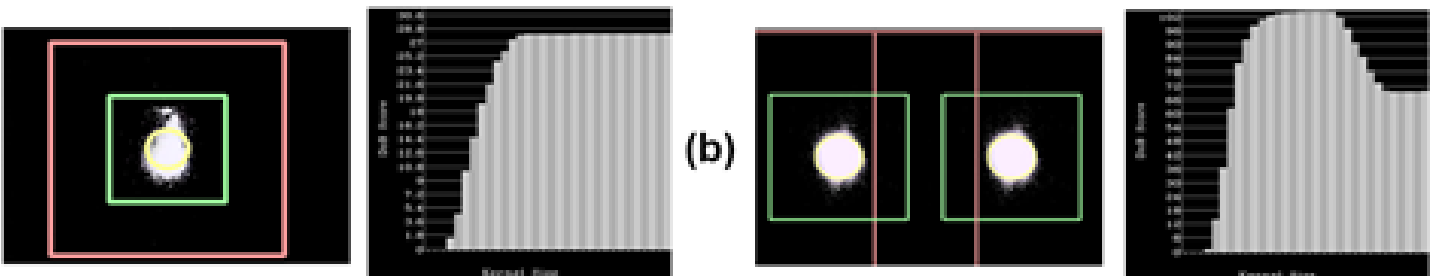

(e)
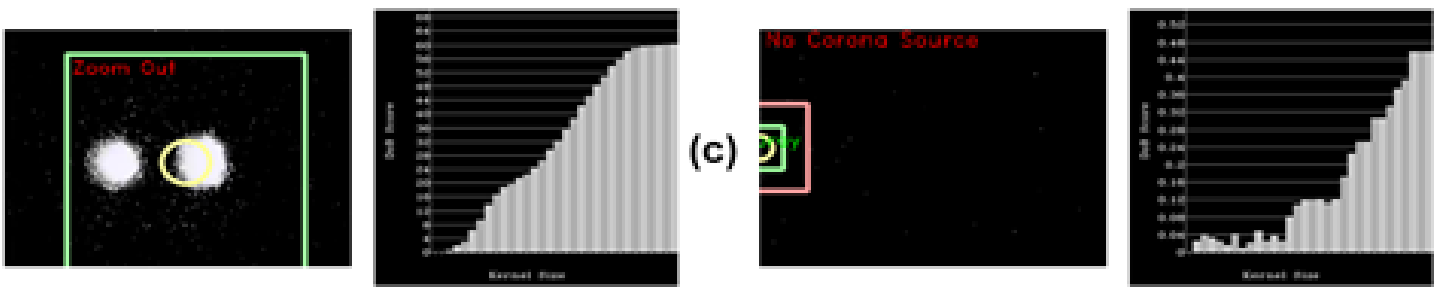

(f)

Figure 1 a) Two examples of UV corona discharge imagery captured at midrange camera gain. (b-f) DoB overlay of greyscale corona image (left) and scale space representation (right). If the score is monotonic increasing (b, c), or nearly so (d), a single visible-band image is sufficient to document the discharge. Well-separated coronas have a smooth but modal score through scale (e), while the score varies erratically through scale for ambient emission or peripheral corona spray (f). 


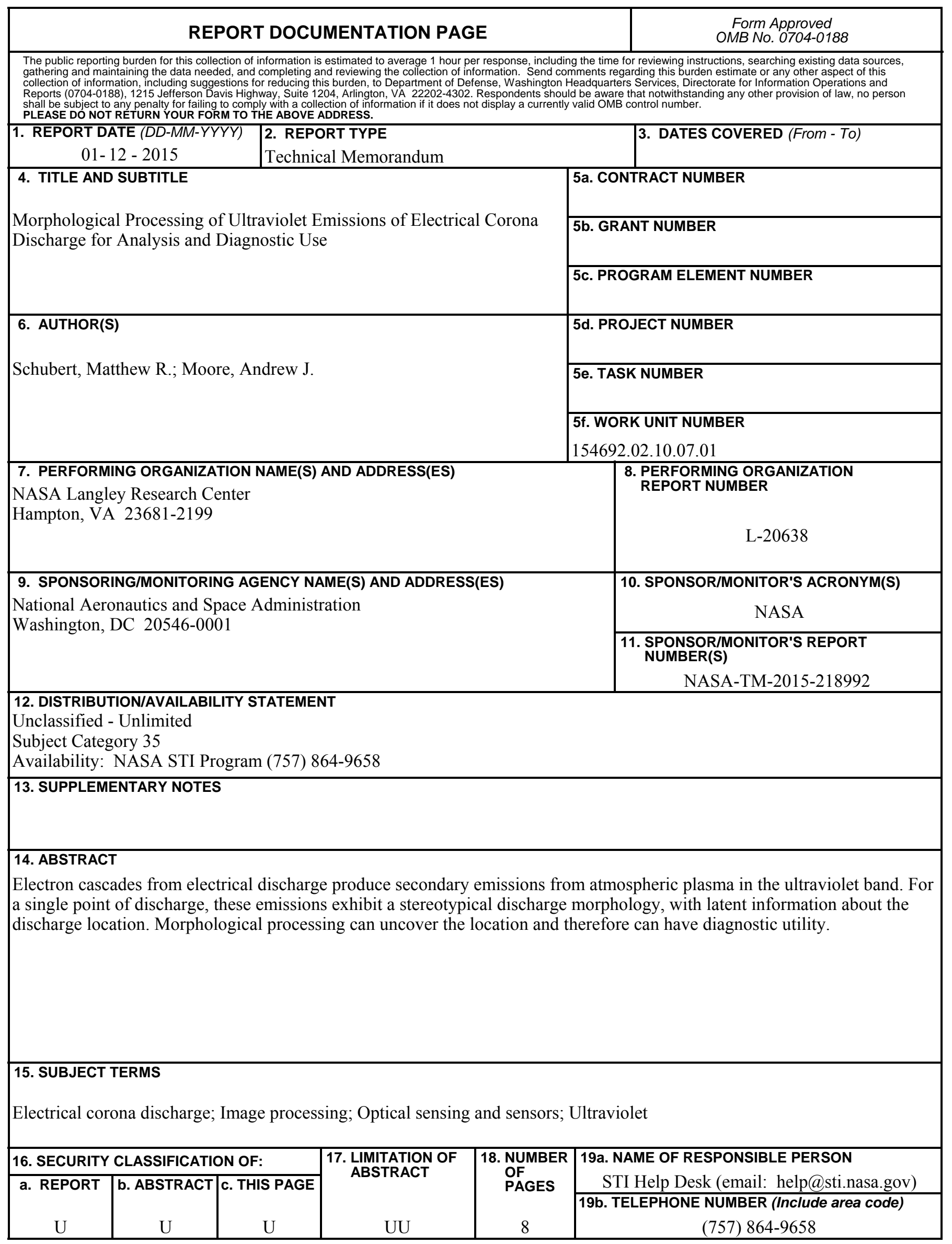

